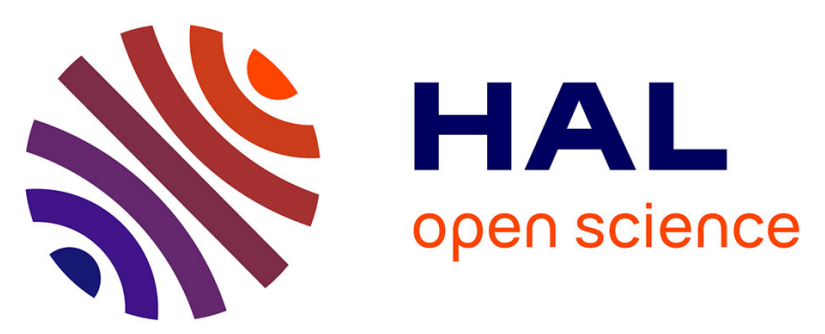

\title{
Methane Pyrolysis: literature survey and comparisons of available data for use in numerical simulations
}

\author{
Guillaume Fau, Nicolas Gascoin, Philippe Gillard, Johan Steelant
}

\section{To cite this version:}

Guillaume Fau, Nicolas Gascoin, Philippe Gillard, Johan Steelant. Methane Pyrolysis: literature survey and comparisons of available data for use in numerical simulations. Journal of Analytical and Applied Pyrolysis, 2013, http://dx.doi.org/10.1016/j.jaap.2013.04.006. 10.1016/j.jaap.2013.04.006 . hal-00868593

\section{HAL Id: hal-00868593 \\ https://hal.science/hal-00868593}

Submitted on 1 Oct 2013

HAL is a multi-disciplinary open access archive for the deposit and dissemination of scientific research documents, whether they are published or not. The documents may come from teaching and research institutions in France or abroad, or from public or private research centers.
L'archive ouverte pluridisciplinaire HAL, est destinée au dépôt et à la diffusion de documents scientifiques de niveau recherche, publiés ou non, émanant des établissements d'enseignement et de recherche français ou étrangers, des laboratoires publics ou privés. 


\title{
Methane Pyrolysis: literature survey and
}

\section{comparisons of available data for use in numerical}

\section{simulations}

\author{
Guillaume Fau, ${ }^{* \dagger}$ Nicolas Gascoin, ${ }^{\dagger}$ Philippe Gillard, ${ }^{\dagger}$ and Johan Steelant \\ University of Orleans, IUT Bourges, 63 avenue de Lattre de Tassigny - 18000 Bourges, France. \\ ${ }^{\dagger}$ European Space research and TEchnology Centre, Keplerlaan 1, 2201 AZ Noordwijk, The \\ Netherlands
}

*Corresponding author: Tel.: +332482380 88. E-mail: guillaume.fau@univ-orleans.fr

\begin{abstract}
Methane pyrolysis has been investigated in the open literature for a number of applications (improvement of fuel cracking, production of hydrogen, aeronautics and space use for cooling). This implies a large panel of experimental conditions and the development of numerous kinetic schemes, all validated for different test ranges. This last decade, a renew of interest is emerging according to the possibility of using methane as jet fuel for hypersonic applications. In this framework, it is required to determine the ability of the existing kinetic schemes to reproduce the chemical behaviour of the fuel during its pyrolysis $(\mathrm{T}>1500 \mathrm{~K}$ and $\mathrm{P}>1 \mathrm{MPa}$ ) in order to use these mechanisms in Computational Fluid Dynamics simulations. Thus, a balance must be found
\end{abstract}


between the accuracy of the predictions and the computations time (linked to the mechanism size). Reviewing a large panel of the experimental and numerical works and then comparing the existing schemes with available data is proposed in this work to estimate their potential (considering, if possible, the maximal stressing conditions). After a first selection, ten mechanisms are quantitatively compared regarding three important species: methane, which reflects the pyrolysis rate; hydrogen, linked to the propulsion efficiency and acetylene which is involved in the coke formation (unwanted effect). The computation time has been also determined and it serves as an additional selection criteria. One model seems to emerge regarding its accuracy and its size. It results in predictions with disagreement lower than $30 \%$ compared to the reference data and in calculation time lower than $1 \mathrm{~s}$ for a simulated time of $10 \mathrm{~s}$ in $0-\mathrm{D}$ configuration.

\section{Introduction}

Hypersonic applications involve the management of a large thermal load applied to the whole structure. The temperature overpasses $1600 \mathrm{~K}$ (Mach 6), which imposes an efficient method to cool the materials. In regards with this objective, the circulation at counterflow of an endothermic fuel is explored as a regenerative cooling system. ${ }^{1,2}$ The thermal degradation of the fuel would act as a heat sink before entering in the combustion chamber. The choice of the fuel is critical and numerous studies have been conducted in order to explore the potential of several hydrocarbons. ${ }^{3-7}$ The experimental analysis of the pyrolyzed products distribution (notably the formation of solid carbon) was one of the fundamental keys of research. ${ }^{6,8}$ In addition, numerical studies are equally essentials in order to get a better understanding of the process and to obtain a better view of the chemistry for very stressing conditions (which are scarcely testable by experimentation). The modeling of such phenomenon is quite a hard task notably in regards with 
the construction of a complete reaction network (which may involves thousands reactions and species). The first models were built manually, based on the theory of the chemical chain reaction elaborated by Bodenstein, and generally laid on the works of Rice (et al.). ${ }^{9-16}$ As example, Willem and Froment ${ }^{17,18}$ proposed a method to develop a kinetic modeling for the thermal decomposition of hydrocarbons by classifying the reactions into 3 different categories (initiation, propagation and termination). Nevertheless, the manual development of a detailed mechanism is fastidious and this explains the latest developments concerning the automated model generation. ${ }^{19-29}$ Tomlin et al..$^{30}$ exposed the main features that such program should have: the structures of the species should be known; all combinations of the given species must be considered; no reaction should appear twice; a sensitivity analysis should delete the unimportant reactions. As an example of such a software, EXGAS $^{31}$ can be cited. It generates kinetic scheme to be used within a chemical solver such as Chemkin Program. ${ }^{32}$ Similarly, the work of Broadbelt et al. $^{23}$ can be mentioned since it uses a complementary approach. RING is another recent example of reaction network generator. ${ }^{29}$ The accuracy of the kinetic mechanisms has been improved through the increased details of the chemical modeling. As a result, this took away the use of such detailed chemistry within multiphysics software for computation cost reasons. Consequently, it appears necessary to reduce the size of the kinetic mechanisms without loss of accuracy using specific reduction methods which raised more recently. ${ }^{33-37}$

In the framework of regenerative cooling, the potential of methane has been succinctly explored $^{38}$ while the majority of studies are generally devoted to more complex molecules (dodecane $,{ }^{39} \mathrm{JP}-10,{ }^{40}$ etc.). However, a certain renew of interest seems to emerge and the present work is proposed in this concern. As a basis, number of researches have been done on the thermal degradation of methane and can be found in the literature. The works realized were, in a first time, essentially experimental and a large panel of different conditions (temperature, 
pressure, reactor, etc.) was considered (according to the study's objectives). As a consequence, an important collection of data has been progressively constituted. A few reviews ${ }^{41,42}$ have been elaborated and permit to gather a part of this large amount of results but they are now quite outdated and it appears necessary to propose an updated work. Another objective of this study is to detect an efficient kinetic model to simulate the methane pyrolysis according to several criteria. First, the context of hypersonic applications implies to exclude a number of mechanisms without direct interest and possible use (e.g. models for specific configurations like catalytic reforming of methane). Secondly, the number of reactions and species has to be limited (250 reactions and 100 species). This is motivated by the need to integrate the kinetic model in a CFD code with the perspective to realize multi-dimensional simulations. Then, a good accuracy is expected (disagreement lower than 10-20 wt.\% with reference data) for the main chemical products while the major PAH (naphthalene, pyrene, styrene, anthracene) should be considered. Lastly, the computations should be made via a CHEMKIN-compatible tool to be interfaced with other CFD codes. ${ }^{43}$ Hence, the mechanisms which are directly available in this format are largely privileged. Finally, due to the difficulties to find such a mechanism which would match all these requirements, some dispensation may be envisaged if only one criterion is not respected.

As a consequence, a large bibliographic review is necessary to list eligible mechanisms and to find experimental and validation data to test the strength of the models. Thus, the first part of this work proposes to review a large number of works devoted to the pyrolysis of methane. Then, ten kinetic schemes have been selected and compared according to the same stressing conditions (high temperature and pressure). The parameters of choice are: the number of species and reactions and the accuracy of some selected species, i.e. methane, hydrogen, acetylene and some PAH. It can be noted for future work that since this review is done in the context of the cooling of hypersonic vehicles, the intrinsic coke formation in case of pyrolysis and the catalytic effect of 
the reactor walls should be two additional critical factors. This requires a specific focus to be proposed in a later study.

\section{Thermal decomposition of methane}

\subsection{Experiments and kinetic modeling}

The light methane fuel presents a high specific heat of combustion, without particular safety issue (compared to hydrogen ${ }^{38}$ ) and with high density if cryogenic. Recent progress on hydrogen generation through methane catalytic degradation strongly increased its interest (e.g. $\left.{ }^{44-48}\right)$. Since the 1900 's, the thermal cracking of methane has been widely studied under numerous different conditions; first, experimentally. ${ }^{41,47,49-72}$ The experiments ${ }^{49-55}$ did not initially include quantification and identification of all the pyrolysis products and radicals. The results were mostly qualitative and they were based on the description of the first primary reactions. Some additional works then proposed numerical modeling and comparisons. A summary of the main studies discussed in this section is proposed in the Supporting Information (Table S1).

Palmer et al. ${ }^{56}$ explored the methane thermal decomposition within mixtures with helium (concentrations between $1 \mathrm{vol} . \%$ and $20 \mathrm{vol} . \%$ ) in a flow system for a temperature range of $1323 \mathrm{~K}-1523 \mathrm{~K}$ and for a pressure close to the atmospheric one $(0.098 \mathrm{MPa})$. Methane was injected in a hot porcelain tube (residence time range from $0.1 \mathrm{~s}$ to $0.9 \mathrm{~s}$ ) and the evolution of its conversion rate as well as the production of ethane, ethylene and acetylene were monitored. Palmer et al. observed that ethylene is the major product, followed by acetylene and ethane. There results were not in adequacy with the other data available in the literature. ${ }^{57}$ The products distribution differs between two experiments like a shock tube and a tubular reactor. Thus, they demonstrated that the global pyrolysis mechanism depends on the experimental conditions. 
Khan and Crynes confirmed this point in their review of methane pyrolysis. ${ }^{41}$ They furnished two interesting tables which summarized the different experiments already done at that time with the associated conditions, mechanisms, kinetic parameters and results. They highlighted that the conditions change the decomposition by impacting the reactions pathway. For example, between $1200 \mathrm{~K}$ and $1400 \mathrm{~K}$, methane firstly decomposes into $\mathrm{CH}_{3}$ and $\mathrm{H}$ radicals while for higher temperatures (1656 K-1965 K), acetylene and hydrogen are the first produced species.

During the 1970's, the researchers attempted to describe and to construct a global kinetic mechanism that could entirely explain the thermal decomposition of methane. Chen et al. ${ }^{60,61}$ proposed a preliminary model based on their experimental results: methane was pyrolyzed in a quartz cylinder considering 4 test temperatures $(995 \mathrm{~K}, 1038 \mathrm{~K}, 1068 \mathrm{~K}$ and $1103 \mathrm{~K})$ at low pressure (0.0033 MPa-0.093 MPa). The monitoring of the decomposition products (hydrogen, ethane, ethylene, acetylene and propylene) was ensured by a Gas Chromatograph (GC). Hydrogen and ethane were the first species detected. The delayed production of ethylene and then of acetylene and of propylene confirmed that $\mathbf{C}_{2} \mathbf{H}_{4}$ is a secondary product while the two others are tertiary one. Based on those observations, Chen et al. proposed the following reaction pathway to explain the methane pyrolysis (with the associated kinetics parameters):

$$
\begin{array}{cc}
\text { Initiation } & \mathrm{CH}_{4} \rightarrow \mathrm{CH}_{3}+\mathrm{H} \\
\text { Step } & \mathrm{H}+\mathrm{CH}_{4} \rightarrow \mathrm{CH}_{3}+\mathrm{H}_{2} \\
2 \mathrm{CH}_{3} \leftrightarrow \mathrm{C}_{2} \mathrm{H}_{6} \\
\begin{array}{c}
\text { Secondary } \\
\text { reaction }
\end{array} \\
\mathrm{CH}_{3}+\mathrm{C}_{2} \mathrm{H}_{6} \leftrightarrow \mathrm{CH}_{4}+\mathrm{C}_{2} \mathrm{H}_{5} \\
\mathrm{C}_{2} \mathrm{H}_{5} \rightarrow \mathrm{C}_{2} \mathrm{H}_{4}+\mathrm{H} \\
\text { Tertiary } & \mathrm{CH}_{3}+\mathrm{C}_{2} \mathrm{H}_{4} \rightarrow \mathrm{C}_{2} \mathrm{H}_{3}+\mathrm{CH}_{4} \\
\text { reaction } & \mathrm{C}_{2} \mathrm{H}_{3} \rightarrow \mathrm{C}_{2} \mathrm{H}_{2}+\mathrm{H} \\
& \mathrm{CH}_{3}+\mathrm{C}_{2} \mathrm{H}_{4} \leftrightarrow \mathrm{n}-\mathrm{C}_{3} \mathrm{H}_{7} \\
& \mathrm{n}-\mathrm{C}_{3} \mathrm{H}_{7} \rightarrow \mathrm{C}_{3} \mathrm{H}_{6}+\mathrm{H}
\end{array}
$$

Chen et al. experimentally highlighted another important phenomenon, not predicted by their mechanism: the autocatalysis (refer to Fig. 4 and Fig. 5 of Ref. ${ }^{61}$ ). They noted that the ethane 
yield (i.e. the amount of a chemical compound -following a specific chemical reaction- divided by the total amount of this specie) begins to rise sharply after a steady state plateau for moderate temperature (about $1000 \mathrm{~K}$ ). According to Lieberman and Noles, ${ }^{73}$ an explanation of such a phenomenon could be the deposit of carbon at the surface of the reactor so that there are some modifications of the chemistry at this level: the carbon-coated surface acts as a catalyst for the reaction. ${ }^{73}$ However, such surface effect was infirmed by Chen et al. ${ }^{61}$

Dean $^{64}$ made further investigation on the autocatalysis and he proposed a mechanism to explain this phenomenon through numerical investigations at $0.058 \mathrm{MPa}$. First, he based his analysis on a model proposed by Roscoe and Thompson. ${ }^{65}$ Dean shows that this mechanism, even if it furnishes good results, is not adequate to explain the ethane increase (autocatalysis) if microscopic reversibility is taken into account. Consequently, the autocatalysis can only be the result of three possible reaction pathways: the cycloaddition reactions between olefins and dienes; the ion-molecule reactions with their very large rate constant and the radical addition on unsaturated compounds. The third assumption was explored. Dean elaborated a model involving 122 species and 438 reactions, which can be reduced depending on the experimental temperature and pressure conditions (e.g. in Ref. ${ }^{61}, 44$ reactions for 25 species are sufficient). Dean isolated the three major reactions which had a significant impact on the agreement between simulation and experiment: the initiation reaction (1), a secondary reaction (4) and a reaction which was not described by Chen et al.$^{60,61}$ and which consisted on the methyl abstraction from cyclopentadiene (Eq. 10).

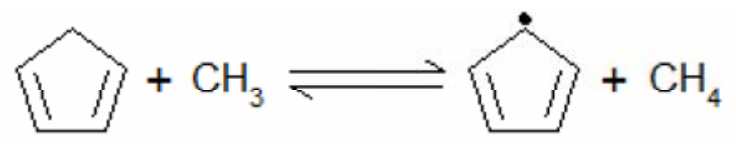


The final model accurately predicts the autocatalysis and it provides a very good estimation of the ethylene production. Nevertheless, acetylene is overpredicted and propylene is slightly underpredicted.

Later, Matheu et al. invalidated Dean's assumption notably by correcting thermodynamic parameters of cyclopentadienyl according to new experimental data. ${ }^{19}$ Then, they proposed a new model constructed by an automatic generator (based on the improved ExxonMobil mechanism generation $\operatorname{code}^{74}$ ) which systematically takes into account the pressure-dependent reactions. This one is constituted of about 100 species involved in 1000 reactions and it has been specially build according to Chen et al. ${ }^{60,61}$ experimental conditions $(0.05-0.1 \mathrm{MPa}$. and $<1100 \mathrm{~K})$. The results were more or less satisfactory (maximum discrepancy of $35 \%$ ) and it predicted the autocatalysis. The authors suggested new pathways to explain this phenomenon and notably the importance of reverse disproportionation of certain species as allene or methane to form allyl and methyl radical (cf. Fig. 12 from $\operatorname{Ref}^{19}$ ).

Billaud et al. $^{66}$ also conducted coupled experimental and numerical studies on methane pyrolysis at $1263 \mathrm{~K}$ and atmospheric pressure. Pure methane was injected in an alumina tube heated by an electric furnace. Two Gas Chromatographs were devoted to the qualitative and quantitative monitoring of the pyrolyzed products. A quantification of the coke formation was performed. After hydrogen (the predominant molecule), ethylene was the most represented species, followed by acetylene and benzene. Regarding the numerical approach, the model was based on 119 reactions and it predicted the production of species ranging from $\mathrm{C}_{2}$ to $\mathrm{C}_{6}$. Billaud et al. realized a sensitivity analysis for a large number of reactions in order to isolate those which have a clear impact on the production of each species. For example, they determined that the formation of $\mathrm{C}_{4} \mathrm{H}_{6}$ was mainly dependent on the reaction (Eq. 7) and on the following one (Eq. $11)$. 


$$
\mathrm{C}_{2} \mathrm{H}_{3}+\mathrm{C}_{2} \mathrm{H}_{4} \rightarrow \mathrm{C}_{4} \mathrm{H}_{6}+\mathrm{H}
$$

Olsvik and Billaud ${ }^{67}$ prolonged these investigations for methane $(93 \%)$ and argon $(7 \%)$ mixtures at $1273 \mathrm{~K}$ and atmospheric pressure in plug flow reactor. Their model was composed of 36 reactions and it predicted the formation and consumption of $\mathrm{CH}_{4}, \mathrm{C}_{2} \mathrm{H}_{2}, \mathrm{C}_{2} \mathrm{H}_{4}, \mathrm{C}_{2} \mathrm{H}_{6}, \mathrm{a}-\mathrm{C}_{3} \mathrm{H}_{4}$ (allene), $\mathrm{p}-\mathrm{C}_{3} \mathrm{H}_{4}$ (propyne) and $\mathrm{C}_{3} \mathrm{H}_{6}$. The authors considered the autocatalysis but no ethane increase was detected in the experiments. Such a difference with the precedent works of Chen et al. and of Dean is attributed to the temperature level since high temperatures lead to the decomposition of ethane.

A recent study ${ }^{68}$ focused on the methane pyrolysis in a shock tube $(1600 \mathrm{~K}-2200 \mathrm{~K}$; 0.25 MPa-0.35 MPa). Bedarev et al. based their work on the Kassel mechanism from the 1930's (4 reactions and 5 species) $)^{52}$ and on another one (21 reactions, 13 species) developed by Hidaka et $a l .{ }^{69}$ The kinetic parameters have been modified by Bedarev et al. The comparison with the experimental data showed that the second mechanism was more suitable to model the chemistry within the shock wave. This work gives a good indication on the need to adapt the kinetic scheme to the configuration of study and to the operating conditions. In addition, Bedarev et al. were among the first to conduct 1-D and 2-D CFD calculations. They showed that only reduced kinetic scheme (less than 30 reactions) can be considered in complex multiphysics numerical modeling.

To conclude on this first point, the authors precise that a number of studies have not been cited despite they were carefully considered either because they were of low interest (in regards with the purpose of this work) or due to their specific and restrictive purpose (e.g. the production of syngas with $\mathrm{CO}_{2}$ and methane degradation).

\subsection{Use of kinetic scheme in numerical simulation}


In the continuity of applying methane pyrolysis in multiphysics configuration, Dahl et al. ${ }^{70}$ proposed a one-dimensional non isothermal mathematical model for the high temperature rapid decomposition of methane into hydrogen and carbon black within a graphite aerosol flow reactor $(1533 \mathrm{~K}-2144 \mathrm{~K})$. The temperature and methane flow rate effects were investigated. Rodat et $a l^{72}$ worked on the solar methane cracking and developed a model to simulate it in a tubular solar chemical reactor using the Dsmoke software. The numerical conversion of methane was compared with experiments and satisfactory results were obtained (mean discrepancies around 12 wt. \%). The other results were more fluctuant (notably regarding the $\mathrm{H}_{2}$ production) due to the limitations of Dsmoke. Sinaki et al ${ }^{75}$ developed a model to predict the production of hydrogen issued from methane pyrolysis. They used a combustion mechanism ${ }^{76}$ and they adjusted the kinetic coefficients to fit them on their experiments. These studies confirm that the kinetic mechanisms are often application-oriented and they have difficulties in representing a large variety of configurations when their size is too small. To cope with this drawback, some large mechanisms can be mentioned. For example, the SPYRO model (cf. Ref ${ }^{77,78}$ ) was initially developed by Dente et al. and it was built and improved over the years with the objective to simulate the cracking of a large panel of hydrocarbons ranging from $\mathrm{C}_{1}$ to $\mathrm{C}_{42}$. Obviously, such performance is balanced by the high number of reactions and species (respectively 3288 and 128, plus 20 radicals). Another example is the COILSIM1D software, which is a fundamental model devoted to the furnace simulation of hydrocarbon steam cracking according to an extended conditions set. $^{79}$

Finally, the work of Davis et al. is one of the rare specifically focusing on methane as a fuel for hypersonic application, ${ }^{38}$ taking benefit from the hydrogen and acetylene formation in case of thermal decomposition. This work is mentioned to exemplify the use of kinetic scheme for applied research. Their multiphysic approach serves to analyze the contribution of the physical 
parameters on the chemistry and the resulting coupled effects. They considered the catalytic and non-catalytic studies on methane pyrolysis, the coke formation and the thermodynamic equilibria of carbon-hydrogen systems. They computed the methane decomposition within a temperature range of $1200 \mathrm{~K}-2200 \mathrm{~K}$ and for a pressure ranging from $0.68 \mathrm{MPa}$ to $3.4 \mathrm{MPa}$ within a Perfectly Stirred Reactor (PSR). The kinetic computations were based on a modified hydrocarbon oxidation scheme (Foelche et al. ${ }^{80}$ ). The methane conversion was found to decrease when the pressure increases, the residence time firstly impacts the formation of the primary species and its increase favors the pyrocarbon formation. Davis et al. found that increasing the temperature does not influence the carbon formation, or even limited it. Such surprising result is one of the reasons for the additional literature survey which should be proposed later in a future work regarding the methane pyrolysis with catalysis and coke formation.

\section{This last study demonstrates that methane combustion studies should be mentioned} because of the associated kinetic description. Indeed, the decomposition of methane is a part of the combustion mechanisms. As a consequence for the readers, methane oxidation ${ }^{81-84}$ and combustion $^{85-88}$ schemes can thus be mentioned. Additional mechanisms are referenced and available in the NIST database. ${ }^{89}$

\section{Quantitative comparisons of kinetic mechanisms}

As presented in the preceding section, numerous experimental data were generated over the years in the open literature. A large number of models were developed, each for a specific condition set. Consequently, a global comparison between all models would be unwise. A selection is thus necessary and this has been done following the criteria mentioned in the introduction. The authors remind that the size of the mechanism (by extension, the computation time) should remain limited. Hence, a number of high detailed models are not considered for this 
work (e.g. kinetic model of 14000 reactions $^{72}$ ). Plus, due to the context of this study, a few number of kinetic models, which are devoted to specific applications (e.g. some models for shock tubes), were omitted since the kinetics of fast combustion process is not compatible to the one of slow pyrolysis one. It can be noted that the research of a mechanism was extended to the field of combustion and to the one of heavy hydrocarbon pyrolysis since none of the criterion given above limit this possibility. Some of the most recognized combustion mechanisms have been tested as well as several heavier hydrocarbons pyrolysis schemes (DCPR, ${ }^{90}$ Westbrook $^{91}$ ). Such extension has several justifications. Considering methane combustion, it was intensively studied and numerous models have been developed. These models integrate the reactions directly devoted to its pyrolysis. Consequently, testing it would reveal their potential to simulate the pure thermal degradation of methane. The combustion mechanism do necessarily contain the pyrolysis schemes and those of pyrolysis for heavy species do necessarily contain the reactions dedicated to smaller hydrocarbons when they consider the secondary schemes with formation and consumption of by-products. So, this work represents an extended use of such mechanisms. In addition, combustion models may integrate soot formations which consider PAH formation. Despite these "exotic" kinetic schemes for a methane pyrolysis application are used outside their range of validation (they were probably less tested under pyrolysis conditions with methane than under those for which they were designed), their behavior is interesting to widen the possibilities in terms of numerical computations.

Totally, the performances (accuracy) of the models of interest are analyzed regarding the number of species and reactions since the selected model should be used in CFD application. The results also serve to determine how the reactions pathway can explain the discrepancies. An overview of the main characteristics of the ten models considered in this work is furnished in Supporting files (Table S2). 
Depending on the kinetic model, the number of species and/or reactions can be multiplied by a factor up to 10 roughly. Such differences is easily understandable because of the application field (e.g. a combustion mechanism would have more species/reactions due to the presence of oxygen), the fuel (the dodecane modeling requires the consideration of more reactions) and by the degree of details used to describe the chemistry (e.g. the consideration of heavy polycyclic aromatic hydrocarbons for example). For practical comparison, the number of reactions/species directly linked to the pyrolysis process -particularly in case of combustion mechanism- is given (see Table S2 and S3 in Supporting Information).

The computations using the mechanisms are made thanks to the chemical solver SENKIN ${ }^{97}$; considering an homogeneous closed batch reactor and for fixed temperature and pressure. The calculations were done on an Intel Zeon workstation (8 processors- $2 \mathrm{GHz} ; 12 \mathrm{~Gb}$ memory).

\subsection{Available experimental results}

Comparisons with experimental data are required in order to highlight the strengths and weaknesses of the models. The survey reviews numbers of results but most of them can not be used for some reasons. First, the experimental conditions and particularly, the type of flow impact the chemistry. Thus, experimentations with plug flow or perfect stirred reactors provide the most adequate results for the present work. Hence, other data are neglected. Secondly, as exposed by Davis et al. ${ }^{38}$ no experiments were conducted at both pressure and temperature of interest (i.e. $>1 \mathrm{MPa}$ and $>1500 \mathrm{~K}$ ). Thus, it is possible to find some works at high temperature but low pressure (e.g. $2000 \mathrm{~K}$ but a pressure of $0.01 \mathrm{MPa}^{98}$ ) or conversely. ${ }^{99}$ This clearly limits the number of studies to be used in the present work. Finally, several authors proposed interesting but partial results due to incomplete species quantification. As an example, Murphy et $a l .^{100}$ pyrolyzed different small hydrocarbons, including methane, in a flow system. Only a few informations are given about the products distribution: methane decomposition, ethylene and 
acetylene productions (expressed in mol.\%). Moreover, the experimental pressure is not precisely mentioned so that it appears difficult to use their data. Comparison with the works of Sun and Gavalas ${ }^{101}$ have been also envisaged but the uncertainties on the effective residence time of methane inside the reactor and on the gas temperature could lead to an unwise comparison (notably the potential high error on the methane conversion).

As a consequence, it appears that only few experimental results are of interest and could be used for testing the selected models. Thus, a comparison has been made with the results furnished by Gordon ${ }^{55}$ and Billaud. ${ }^{66}$ Despite the conditions of temperature and pressure are not as stressing as expected and despite their test conditions are roughly similar, this comparison permits to have a first appreciation.

For clarity reasons, only the major species are plotted when comparing experimental and numerical data. The agreement between the computations -whatever the mechanism- and the Gordon's experiments (1280 K/0.1 MPa) is unsatisfactory for most of the species (Figure 1). The methane consumption is more and more underpredicted regarding the pyrolysis progress (about $98 \mathrm{~mol} \%$ of numerically remaining methane against 89 mol.\% experimentally for $1.5 \mathrm{~s}$ Figure 1a). For the other species, the discrepancies largely exceed a threshold of $50 \%$ for all the mechanism, excluding the Konnov's one (Figure 1b-c-d). Such discrepancies are linked with the error made on the methane consumption and the low proportion of the other species which magnifies the difference (e.g. for $\mathrm{C}_{2} \mathrm{H}_{2}$, the comparison is made for experimental molar fraction range of $0.04 \mathrm{~mol} . \%-0.39 \mathrm{~mol} \%$ ). It is assumed that the test conditions are largely responsible for this disagreement (reactor nature, reactor configuration, important surface/volume ratio, product sampling and analysis and temperature).

Figure 1 should be placed here 
The mechanisms were then compared to Billaud's conditions (1263 K, $0.1 \mathrm{MPa})$. For this case, the discrepancies between computations and experiment are more fluctuant during the simulation time. For methane consumption (Figure 2a), the profiles are similar to those from the precedent comparison with Gordon's data but the discrepancies remain more limited (lower than $5 \%$ for the first $4.5 \mathrm{~s}$ ). Westbrook's and Dean's C1-C4 mechanisms return the most accurate predictions considering the global computations time. For hydrogen, the results are mixed (Figure $2 b$ ). Globally, two trends are observable. The first one consists on a primary decrease of the disagreement followed by a raise and then a plus or minus plateau. Such trend is encountered for Leeds', Westbrook's, GRI-MECH's and Konnov's models. Regarding the other mechanisms for the first second of time, it can be noted an increase of the disagreement and then a plus or minus stabilization. Totally, concluding on the most efficient mechanism for the hydrogen prediction is too hazardous due to such fluctuations. Then, for $\mathrm{C}_{2} \mathrm{H}_{2}$, the discrepancies exceed $50 \%$ for all computation durations, excluding for Hamdullahpur's results which are acceptable (between $10 \%$ and $30 \%$ - Figure 2c). This is an important point according to the purpose of this comparison. Indeed, acetylene is one of the "key species" in regards with coke production, which formation relies on the appropriate estimation of this compound. Considering ethylene production, the predictions are as mixed as for the hydrogen ones but with a global better agreement (Figure 2d). Westbrook's and Dean's mechanisms could be considered as more efficient than other schemes. Finally, a comparison was also made for benzene (Figure 2e). The disagreement is important and only Dean's C1 and Dagaut's results fall under a threshold of $50 \%$.

Figure 2 should be placed here 
The median and minimal discrepancy values for the four main species have been calculated (see Table S4 and S5 in Supporting Information) and highlight several points: First, no mechanism return accurate results for the 4 species (based on a threshold value of $50 \%$ ). GRIMECH's, Sung, Dean's C1 and C1-C4, Westbrook's and Hamdullahpur's models demonstrate the most efficiency with three predictions lower than $50 \%$. Among these, the ones of Hamdullahpur and Westbrook seem to be quite superior. Equally, it appears that the accuracy is not linked to the number of reactions for a considered species. Finally, it appears that the accuracy is linked to the simulation time. Thus, it can be noted that the mechanisms are more efficient for the first and half second of time to predict the methane consumption and the hydrogen production while a better agreement is found for ethylene and acetylene for a time higher than $4 \mathrm{~s}$. Totally, it could be assumed that all these differences and observations should be related to two points: in the one hand the number of considered reactions and their corresponding Arrhenius parameters and on the other hand the modeling of quite complex experiments by 0-D simulations.

\subsection{Further numerical investigations}

Due to the lack of experimental data, it is proposed to further appreciate the selected models by confronting their predictions with the computations made by Davis et al. ${ }^{38}$ where the conditions are in close agreement with those expected onboard an hypersonic vehicle. Davis et al. simplified the mechanism elaborated by Foelsche et $_{\text {al. }}{ }^{80}$ (642 reversible reactions and 107 species to model jet fuels -kerosene) and they realized non equilibrium calculations. The results from Davis et al. do not constitute validation data for the present work but they have the merit to exist and to illustrate the composition which may be expected under real hypersonic conditions. Plus it represents the opportunity to consider another mechanism which was not available to the present authors (the one of Foelsche et al.). Moreover, Davis et al. conducted additional work to have a 
numerical validation thanks to several complementary equilibrium calculations. Finally, since these results are the only ones which were found in appropriate conditions for hypersonic use, these data deserve to be mentioned. First comparisons are made at $1700 \mathrm{~K}$ and $0.67 \mathrm{MPa}$ (Figure 3). It can be noted that the Konnov's mechanism clearly differs from others and it returns the worst predictions whatever the species. Regarding the methane consumption (Figure 3a), excluding the Westbrook's and Dagaut's models, the disagreement never overpasses $50 \%$. Dean's and Hamdullahpur's models -and in a lower extent the Sung's one- are the most accurate (mean disagreement respectively equal to $6 \%, 7 \%$ and $9 \%$ ). Considering the hydrogen production (Figure $3 \mathrm{~b}$ ), the disagreement is lower than $50 \%$ for all the mechanisms after $1 \mathrm{~ms}$. GRI-MECH's, Dagaut's, Leeds' and Westbrook's models are relatively less accurate (mean discrepancy between $36 \%$ and $42 \%$ ) than the other ones (close to $30 \%$ ). The results for acetylene are more contrasted and higher discrepancies are observed (generally higher than $50 \%)$. Dagaut's mechanism is the only one which returns discrepancy lower than the threshold for the overall duration. As previously, the results for ethylene are mixed (Figure 3d). GRIMECH's and Westbrook's predictions are quite worse with a mean discrepancy of about $55 \%$. Considering this condition set, it can be concluded that both Hamdullahpur's and Dean's mechanisms globally present similar predications than Davis' calculations.

\section{Figure 3 should be placed here}

Another comparison is proposed with more stressing conditions ( $2000 \mathrm{~K}$ and $3.4 \mathrm{MPa})$. As the precedent set, Konnov's predictions are deficient. For all the other mechanisms excluding the Westbrook's and Dagaut's ones, the agreement for methane decomposition (Figure 4a) appears satisfactory (lower than $50 \%$ ). Dean's models, and, in a lower extent, DCPR's one are the more accurate (maximum disagreement respectively equal to $21.33 \%$ and $45.20 \%$ ). Considering the 
hydrogen production (Figure 4b), the disagreement is lower than $50 \%$ for all the mechanisms after $1 \mu \mathrm{s}$. As for methane consumption, Dean's models show good results (mean discrepancy close to $10 \%$ ) as Hamdullahpur's and Sung's ones (respectively $10 \%$ and $11 \%$ ). The results for acetylene (Figure 3c) are more contrasted and higher discrepancies are observed (> 50\%). Hamdullahpur's predictions are the closest from Davis' ones regarding the overall duration (mean discrepancy close $19.5 \%$ ). Totally, Hamdullahpur's and Dean-C1's results equally present better agreement with Davis' computations.

\section{Figure 4 should be placed here}

\subsection{Computation time and accuracy}

To complete the appreciation of these models, the computation time has to be considered as an important criterion (regarding the integration in a CFD code). This one is directly linked with the number of reactions (Table 1). The computation time should not overpass one second for simulating $10 \mathrm{~s}$ of real time to be later implemented in a CFD code. This condition is fulfilled by the five smallest mechanisms (Table 1). The calculation time has also to be compared with the accuracy of the model's predictions and a good balance should be found. The methane decomposition and the hydrogen and acetylene productions are parameters of interest regarding the simulation of hypersonic application. Consequently, a threshold of $30 \%$ of discrepancy could be fixed as criterion for these species. In Table 1, the values in red represent a deflection compared to the criteria. No mechanism entirely fulfills the requirements for each criterion. The Hamdullahpur's model appears the best compromise regarding the global accuracy. This is why it could be selected for future use in a CFD code.

\section{Table 1 should be placed here}

\section{Conclusions}


The pyrolysis of hydrocarbons is investigated since the 1900's for numerous applications linked to the products generation and to the energy conversion. Considering methane, the conversion rate and the product distribution are clearly influenced by the experimental conditions such as the temperature, the pressure and the reactor nature. Thus, numerical simulation is preferred for such multiphysics study and this required to test the existing kinetic schemes and to validate them.

The literature survey showed that the products formation and the associated chemical mechanisms depend on the experimental test conditions. Combustion mechanisms were also considered since they contain pyrolysis reactions and are often used by the pyrolysis scientific community to conduct reactive studies in absence of oxygen. The limitations generally imposed in terms of species and/or reactions number implies that the corresponding schemes are unable to cover a wide diversity of applications. The way the main species are produced during the methane pyrolysis has been briefly described trough the elementary presentation of the relevant chemical mechanisms. The effect of the reactor's surface has been briefly mentioned and this will be detailed in a future work considering in addition the coupled coke formation. The use of methane kinetic scheme in CFD applications has been reviewed and an acceptable size of the mechanism has been proposed (of the order of few tenths of reactions).

Then, the available detailed kinetic mechanisms for the methane pyrolysis have been tested and compared to existing experimental and numerical data to determine their accuracy. The differences between the mechanisms were explained by comparing the reactions sets. A compromise between accuracy and computation cost clearly shows the advantage of the Hamdullahpur's mechanism regarding the current available data. Nevertheless, this work also highlights a clear lack of results for stressing conditions. Performing experimentation at high pressure and high temperature ( $1500 \mathrm{~K}$ and 30 bar) would be a real benefit not only for getting a 
better view of methane pyrolysis but also to have better tools to appreciate and to extent the validity domain of several kinetic models. This experimental step is expected to be achieved in the coming years by the present authors .

\section{Acknowledgments}

This work was supported by the ESA-ESTEC, Contract 4000101998/10/NL/PA. The authors would like to sincerely thank M. Bouchez and B. Le Naour from MBDA-France for their help involving this project.

\section{Supporting information available for Publication}

Tables S1-S5 present: an overview table summarizing the main experimental methane pyrolysis studies and others giving the characteristics of available kinetic schemes suitable for methane pyrolysis, giving the associated number of reactions with corresponding distribution with respect to the main species of interest and finally giving the mean discrepancies found between the computation and the experiment. This information is available free of charge via the Internet at http://pubs.acs.org.

\section{Reference}

(1) Daniau, E.; Bouchez, M.; Herbinet, O.; Marquaire, P.; Gascoin, N.; Gillard, P. In Fuel reforming for scramjet thermal management and combustion optimization; European Conference For Aerospace Sciences: Moscow, Russia, 2005.

(2) Steelant, J. In Sustained Hypersonic Flight in Europe: First Technology Achievements within LAPCAT II; 17th AIAA International Space Planes and Hypersonic Systems and Technologies Conference: San Francisco, California, 2011; p. 2243. 
(3) Huang, H.; Sobel, D.; Spadaccini, L. In Endothermic heat-sink of hydrocarbon fuels for scramjet cooling; 38th AIAA/ASME/SAE/ASEE Joint Propulsion Conference \& Exhibit: Indianapolis, Indiana, 2002; p. 3871.

(4) Linne, D.; Meyer, M. In Evaluation of heat transfer and thermal stability of supercritical JP-7 fuel; 33rd AIAA/ASME/SAE/ASEE Joint Propulsion Conference \& Exhibit: Seattle, Washington, 1997; p. 3041.

(5) Liu, G.; Han, Y.; Wang, L.; Zhang, X.; Mi, Z. Supercritical thermal cracking of N dodecane in presence of several initiative additives: Products distribution and kinetics. Energy Fuels 2008, 22, 3960-3969.

(6) Edwards, T. Liquid Fuels and Propellants for Aerospace Propulsion : 1903 - 2003 Introduction. J. Propul. Power 2003, 19, 1089-1107.

(7) Widegren, J.; Bruno, T. Thermal decomposition kinetics of kerosene-based rocket propellants. 2. RP-2 with three additives. Energy Fuels 2009, 23, 5523-5528.

(8) Gascoin, N.; Abraham, G.; Gillard, P. Thermal and Hydraulic Effects of Coke Deposit in Hydrocarbon Pyrolysis Process. J. Thermophys Heat Transfer 26, 57-65.

(9) Rice, F. A theory of chemical reactivity. J. Am. Chem. Soc. 1923, 45, 2808-2820.

(10) Rice, F. The Thermal Decomposition of Organic Compounds from the Standpoint of Free Radicals. I. Saturated Hydrocarbons. J. Am. Chem. Soc. 1931, 53, 1959-1972.

(11) Rice, F.; Johnston, W.; Evering, B. The Thermal Decomposition of Organic Compounds from the Standpoint of Free radicals. II. Experimental Evidence of The Decomposition of Organic Compounds into Free Radicals. J. Am. Chem. Soc. 1932, 54, 3529-3543. 
(12) Rice, F. The Thermal Decomposition of Organic Compounds from the Standpoint of Free Radicals. III. The Calculation of the Products Formed from Paraffi Hydrocarbons. Journal of the American Chemical Society 1933, 55, 3035-3040.

(13) Rice, F.; Dooley, M. The Thermal Decomposition of Organic Compounds from the Standpoint of Free Radicals. IV. The Dehydrogenation of Paraffin Hydrocarbons and the Strength of the C-C Bond. J. Am. Chem. Soc. 1933, 55, 4245-4247.

(14) Rice, F.; Johnston, W. The Thermal Decomposition of Organic Compounds from the Standpoint of Free Radicals. V. The Strength of Bonds in Organic Molecules. J. Am. Chem. Soc. 1934, 56, 214-219.

(15) Rice, F.; Herzfeld, K. The Thermal Decomposition of Organic Compounds from the Standpoint of Free Radicals. VI. The Mechanism of Some Chain Reactions. J. Am. Chem. Soc. 1934, 56, 284-289.

(16) Kossiakoff, A.; Rice, F. Thermal decomposition of hydrocarbons, resonance stabilization and isomerization of free radicals. J. Am. Chem. Soc. 1943, 65, 590-595.

(17) Willems, P.; Froment, G. Kinetic modeling of the thermal cracking of hydrocarbons. 1. Calculation of frequency factors. Ind. Eng. Chem. Res. 1988, 27, 1959-1966.

(18) Willems, P.; Froment, G. Kinetic modeling of the thermal cracking of hydrocarbons. 2. Calculation of activation energies. Ind. Eng. Chem. Res. 1988, 27, 1966-1971.

(19) Matheu, D.; Dean, A.; Grenda, J.; Green, W. Mechanism generation with integrated pressure dependence: A new model for methane pyrolysis. J. Phys. Chem. A 2003, 107, 85528565. 
(20) Quann, R.; Jaffe, S. Structure-oriented lumping: describing the chemistry of complex hydrocarbon mixtures. Ind. Eng. Chem. Res. 1992, 31, 2483-2497.

(21) Grenda, J.; Androulakis, I.; Dean, A.; Green, W. Application of computational kinetic mechanism generation to model the autocatalytic pyrolysis of methane. Ind. Eng. Chem. Res. 2003, 42, 1000-1010.

(22) Clymans, P.; Froment, G. Computer-generation of reaction paths and rate equations in the thermal cracking of normal and branched paraffins. Comput. Chem. Eng. 1984, 8, 137-142.

(23) Broadbelt, L.; Stark, S.; Klein, M. Computer generated pyrolysis modeling: on-the-fly generation of species, reactions, and rates. Ind. Eng. Chem. Res. 1994, 33, 790-799.

(24) Prickett, S.; Mavrovouniotis, M. Construction of complex reaction systems-I. Reaction description language. Comput. Chem. Eng. 1997, 21, 1219-1235.

(25) VanGeem, K.; Reyniers, M.; Marin, G.; Song, J.; Green, W.; Matheu, D. Automatic reaction network generation using RMG for steam cracking of n-hexane. AIChE J. 2006, 52, $718-730$.

(26) Song, J. Building robust chemical reaction mechanisms: next generation of automatic model construction software. PhD Thesis, Massachusetts Institute of Technology, 2004.

(27) Maio, F. Di; Lignola, P. KING, a KInetic Network Generator. Chem. Eng. Sci. 1992, 47, 2713-2718.

(28) Green, W.; Barton, P.; Bhattacharjee, B.; Matheu, D.; Shwer, D.; Song, J.; Sumathi, R. Computer construction of detailed chemical kinetic models for gas-phase reactors. Ind. Eng. Chem. Res. 2001, 40, 5362-5370. 
(29) Rangarajan, S.; Bhan, A.; Daoutidis, P. Rule-Based Generation of Thermochemical Routes to Biomass Conversion. Ind. Eng. Chem. Res. 2010, 49, 10459-10470.

(30) Tomlin, A.; Turányi, T.; Pilling, M. In Comprehensive Chemical Kinetics; Elsevier, 1997; Vol. 35, pp. 293-437.

(31) Warth, V.; Battin-Leclerc, F.; Fournet, R.; Glaude, P. Computer based generation of reaction mechanisms for gas-phase oxidation. Comput. Chem. 2000, 24, 541-560.

(32) Kee, R.; Rupley, F.; Meeks, E.; Miller, J. CHEMKIN-III: A FORTRAN chemical kinetics package for the analysis of gas-phase chemical and plasma kinetics. Sandia National Laboratories Report 1996, 3-164.

(33) Elliott, L.; Ingham, D.; Kyne, A.; Mera, N.; Pourkashanian, M.; Whittaker, S. Reaction mechanism reduction and optimisation for modelling aviation fuel oxidation using standard and hybrid genetic algorithms. Comput. Chem. Eng. 2006, 30, 889-900.

(34) He, K.; Androulakis, I.; Ierapetritou, M. On-the-fly reduction of kinetic mechanisms using element flux analysis. Chem. Eng. Sci. 2010, 65, 1173-1184.

(35) Pepiot, P. In Systematic reduction of large chemical mechanisms; 4th Joint Meeting of the U.S. Sections of the Combustion Institute: Philadelphia, Pennsylvania, 2005.

(36) Lu, T.; Law, C. A directed relation graph method for mechanism reduction. Proc. Combust. Inst. 2005, 30, 1333-1341.

(37) Norris, A. In Automated simplification of full chemical mechanisms; 33rd AIAA/ASME/SAE/ASEE Joint Propulsion Conference: Seattle, Washington, 1997; p. 3115. 
(38) Davis, K.; Cerven, W.; Solomon, W. In The use of methane as a fuel for hypersonic propulsion; 31st AIAA/ASME/SAE/ASEE Joint Propulsion Conference and Exhibit: San Diego, California, 1995; p. 2769.

(39) Gascoin, N.; Abraham, G.; Gillard, P. Synthetic and jet fuels pyrolysis for cooling and combustion applications. J. Anal. Appl. Pyrolysis 2010, 89, 294-306.

(40) Leylegian, J.; Chinitz, W.; Benel, G.; Castaldi, M. In Continued Investigation of Short Contact Time Reactors for Regeneratively-Cooled Hypersonic Vehicles; 46th AIAA/ASME/SAE/ASEE Joint Propulsion Conference \& Exhibit: Nashville, Tennessee, 2010; p. 6791.

(41) Khan, M.; Crynes, B. Survey of recent methane pyrolysis literature. Ind. Eng. Chem. Res. 1970, 62, 54-59.

(42) Billaud, F.; Baronnet, F.; Freund, E.; Busson, C.; Weill, J. Thermal decomposition of methane: bibliographic study and proposal of a mechanism. Rev. I. Fr. Petrol. 1989, 44, 813823.

(43) Gascoin, N.; Gillard, P. Dynamic Study of Coupled Heavy Hydrocarbon Pyrolysis and Combustion. Combust. Sci. Technol. 2012.

(44) Pinilla, J.; Suelves, I.; Lázaro, M.; Moliner, R.; Palacios, J. Parametric study of the decomposition of methane using a $\mathrm{NiCu} / \mathrm{Al} 2 \mathrm{O} 3$ catalyst in a fluidized bed reactor. Int. J. Hydrogen Energy 2009, 35, 9801-9809.

(45) Ashok, J.; Reddy, P.; Raju, G. Catalytic Decomposition of Methane to Hydrogen and Carbon Nanofibers over Ni- Cu- SiO2 Catalysts. Energy Fuels 2008, 23, 5-13. 
(46) Hussain, S.; Gul, S.; Mazhar, M.; Anjum, D.; Larachi, F. Effect of surface structure on the catalytic behavior of $\mathrm{Ni}: \mathrm{Cu} / \mathrm{Al}$ and $\mathrm{Ni}: \mathrm{Cu}$ : $\mathrm{K} / \mathrm{Al}$ catalysts for methane decomposition. $J$. Nat. Gas Chem. 2008, 17, 374-382.

(47) Abanades, S.; Flamant, G. Experimental study and modeling of a high-temperature solar chemical reactor for hydrogen production from methane cracking. Int. J. Hydrogen Energy 2007, $32,1508-1515$.

(48) Dunker, A.; Ortmann, J. Kinetic modeling of hydrogen production by thermal decomposition of methane. Int. J. Hydrogen Energy 2006, 31, 1989-1998.

(49) Bone, W.; Coward, H. The thermal decomposition of hydrocarbons. Part I. [Methane, ethane, ethylene, and acetylene.]. J. Chem. Soc. Trans. 1908, 93, 1197-1225.

(50) Slater, W. The influence of different surfaces on the decomposition of methane. J. Chem. Soc. Trans. 1916, 109, 160-164.

(51) Cantelo, R. The thermal decomposition of methane. J. Phys. Chem. 1924, 28, 1036-1048.

(52) Kassel, L. The thermal decomposition of methane. J. Am. Chem. Soc. 1932, 54, 39493961.

(53) Wheeler, T. The thermal decomposition of methane. Recl. Trav. Chim. Pays-Bas 1932, $51,342-344$.

(54) Rice, F.; Dooley, M. The Thermal Decomposition of Organic Compounds from the Standpoint of Free Radicals. XII. The Decomposition of Methane. J. Am. Chem. Soc. 1934, 56, $2747-2749$. 
(55) Gordon, A. Pyrolysis of methane flowing through a porcelain tube in the region $1000^{\circ} . J$. Am. Chem. Soc. 1948, 70, 395-401.

(56) Palmer, H.; Lahaye, J.; Hou, K. Kinetics and mechanism of the thermal decomposition of methane in a flow system. J. Phys. Chem. 1968, 72, 348-353.

(57) Eisenberg, B.; Bliss, H. Kinetics of methane pyrolysis. Chem. Eng. Prog. Symp. Ser. 1967, 63, 3-17.

(58) Kawahara, Y. Decomposition of hydrocarbons in a microwave discharge. I. Methane. Effect of power. J. Phys. Chem. 1969, 11, 1648-1651.

(59) Makarov, K.; Pechik, V. Kinetics of methane pyrolysis under conditions of pyrolytic carbon formation. Carbon 1974, 12, 391-403.

(60) Chen, C.; Back, M.; Back, R. The Thermal decomposition of methane. I. Kinetics of the primary decomposition to $\mathrm{C} 2 \mathrm{H} 6+\mathrm{H} 2$; Rate constant for the homogeneous unimolecular dissociation of methane and its pressure dependence. Can. J. Chem. 1975, 53, 3580-3590.

(61) Chen, C.; Back, M.; Back, R. The thermal decomposition of methane. II. Secondary reactions, autocatalysis and carbon formation; non-Arrhenius behaviour in the reaction of $\mathrm{CH} 3$ with ethane. Can. J. Chem. 1976, 54, 3175-3184.

(62) Tabayashi, K.; Bauer, S. The early stages of pyrolysis and oxidation of methane. Combust. Flame 1979, 34, 63-83.

(63) Lucas, P.; Marchand, A. Pyrolytic carbon deposition from methane: an analytical approach to the chemical process. Carbon 1990, 28, 207-219. 
(64) Dean, A. Detailed kinetic modeling of autocatalysis in methane pyrolysis. J. Phys. Chem. 1990, $145,16-37$.

(65) Roscoe, J.; Thompson, M. Thermal decomposition of methane: Autocatalysis. Int. J. Chem. Kinet. 1985, 17, 967-990.

(66) Billaud, F.; Gueret, C.; Weill, J. Thermal decomposition of pure methane at $1263 \mathrm{~K}$. Experiments and mechanistic modelling. Thermochim. Acta 1992, 211, 303-322.

(67) Olsvik, O.; Billaud, F. Modelling of the decomposition of methane at $1273 \mathrm{~K}$ in a plug flow reactor at low conversion. J. Anal. Appl. Pyrolysis 1993, 25, 395-405.

(68) Bedarev, I.; Parmon, V.; Fedorov, A.; Fedorova, N.; Fomin, V. Numerical study of methane pyrolysis in shock waves. Combust. Explo. Shock+ 2004, 40, 580-590.

(69) Hidaka, Y.; Nakamura, T.; Tanaka, H.; Inami, K.; Kawano, H. High temperature pyrolysis of methane in shock waves. Rates for dissociative recombination reactions of methyl radicals and for propyne formation reaction. Int. J. Chem. Kinet. 1990, 22, 701-709.

(70) Dahl, J.; Barocas, V.; Clough, D.; Weimer, A. Intrinsic kinetics for rapid decomposition of methane in an aerosol flow reactor. Int. J. Hydrogen Energy 2002, 27, 377-386.

(71) Trommer, D.; Hirsch, D.; Steinfeld, A. Kinetic investigation of the thermal decomposition of $\mathrm{CH} 4$ by direct irradiation of a vortex-flow laden with carbon particles. Int. J. Hydrogen Energy 2004, 29, 627-633.

(72) Rodat, S.; Abanades, S.; Coulié, J.; Flamant, G. Kinetic modelling of methane decomposition in a tubular solar reactor. Chem. Eng. J. 2009, 146, 120-127. 
(73) Lieberman, M. L.; Noles, G. T. Effect of flow rate on gas composition during the isothermal pyrolysis of methane. Carbon 1974, 12, 689-693.

(74) Matheu, D. Integrated Pressure-Dependence in Automated mechanism generation: a new tool for building gas-phase kinetic models. PhD Thesis, Massachusetts Institute of Technology, 2003.

(75) Sinaki, M.; Matida, E.; Hamdullahpur, F. Development of a reaction mechanism for predicting hydrogen production from homogeneous decomposition of methane. Int. J. Hydrogen Energy 2011, 1-9.

(76) Appel, J.; Bockhorn, H.; Frenklach, M. Kinetic modeling of soot formation with detailed chemistry and physics: laminar premixed flames of $\mathrm{C} 2$ hydrocarbons. Combust. Flame 2000, $121,122-136$.

(77) Dente, M.; Ranzi, E.; Goossens, A. Detailed prediction of olefin yields from hydrocarbon pyrolysis through a fundamental simulation model (SPYRO). Comput. Chem. Eng. 1979, 3, 6175.

(78) VanGoethem, M.; Kleinendorst, F.; VanLeeuwen, C.; N, V. Equation-based SPYRO ® model and solver for the simulation of the steam cracking process. Comput. Chem. Eng. 2001, $25,905-911$.

(79) VanGeem, K.; Marin, G. In Computer aided design and optimization of olefin production plants; European Symposium on Computer Aided Process Engineering: Ischia, Italy, 2010.

(80) Foelsche, R.; Keen, J.; Solomon, W.; Buckleyt, P.; Corporan, E. Non-Equilibrium Combustion Models for Fuel Rich Gas Generators. AIAA J. Spacecraft Rockets 1994, 10. 
(81) Bendtsen, A.; Glarborg, P.; Dam-Johansen, K. Chemometric analysis of a detailed chemical reaction mechanism for methane oxidation. Chemometr. Intell. Lab. 1998, 44, 353361.

(82) Webley, P.; Tester, J. Fundamental kinetics of methane oxidation in supercritical water. Energy Fuels 1991, 5, 411-419.

(83) Sung, C.; Law, C.; Chen, J. An augmented reduced mechanism for methane oxidation with comprehensive global parametric validation. Symp. (Int.) Combust. 1998, 27, 295-304.

(84) Hughes, K.; Turányi, T.; Clague, A.; Pilling, M. Development and testing of a comprehensive chemical mechanism for the oxidation of methane. Int. J. Chem. Kinet. 2001, 33, $513-538$.

(85) Konnov, A. In Development and validation of a detailed reaction mechanism for the combustion of small hydrocarbons; 28-th Symposium (Int.) on Combustion. Abstr. Symp. Pap: Edinburgh, Scotland, 2000; p. 317.

(86) Bell, J.; Day, M.; Grcar, J. Numerical simulation of premixed turbulent methane combustion. Proc. Combust. Inst. 2002, 29, 1987-1993.

(87) Bilger, R.; Storner, S.; Kee, R. On reduced mechanisms for methane---air combustion in nonpremixed flames. Combust. Flame 1990, 80, 135-149.

(88) Glarborg, P.; Lilleheie, N.; Byggstoyl, S.; Magnussen, B.; Kilpinen, P.; Hupa, M. A reduced mechanism for nitrogen chemistry in methane combustion. Symp. (Int.) Combust. 1992, 24, 889-898.

(89) http://kinetics.nist.gov/CKMech/ModelsSearch.jsp. 
(90) Daniau, E.; Bouchez, M.; Bounaceur, R.; Battin-Leclerc, F.; Marquaire, P.; Fournet, R. In Contribution to Scramjet active cooling analysis using n-dodecane decomposition model as a generic endothermic fuel; 12th AIAA International Space Planes and Hypersonic Systems and Technologies: Norfolk, Virginia, 2003; p. 6920.

(91) Westbrook, C.; Pitz, W.; Herbinet, O.; Curran, H.; Silke, E. A comprehensive detailed chemical kinetic reaction mechanism for combustion of n-alkane hydrocarbons from n-octane to n-hexadecane. Combust. Flame 2009, 156, 181-199.

(92) Sung, C.; Li, B.; Wang, H.; Law, C. Structure and sooting limits in counterflow methane/air and propane/air diffusion flames from 1 to 5 atmospheres. Symp. (Int.) Combust. 1998, 27, 1523-1529.

(93) Gri-mech 3.0 - http://www.me.berkeley.edu/gri_mech/.

(94) Gupta, G.; Hecht, E.; Zhu, H.; Dean, A.; Kee, R. Gas-phase reactions of methane and natural-gas with air and steam in non-catalytic regions of a solid-oxide fuel cell. J. Power Sources 2006, 156, 434-447.

(95) Dagaut, P.; Reuillon, M.; Cathonnet, M. SHORT COMMUNICATION High Pressure Oxidation of Liquid Fuels from Low to High Temperature. 3. n-Decane. Comb. Sci. Technol. 1994, 103, 349-359.

(96) Walters, K.; Dean, A.; Zhu, H.; Kee, R. Homogeneous kinetics and equilibrium predictions of coking propensity in the anode channels of direct oxidation solid-oxide fuel cells using dry natural gas. J. Power Sources 2003, 123, 182-189.

(97) Kee, R.; Rupley, F.; Miller, J. Sandia Laboratories Report, SAND 89-8009B, 1993. 
(98) Holmen, A.; Rokstad, O.; Solbakken, A. High-temperature pyrolysis of hydrocarbons. I. Methane to acetylene. Ind. Eng. Chem. Res. 1976, 15, 439-444.

(99) Larkins, F.; Khan, A. Pyrolysis of Methane to Higher Hydrocarbons: A Thermodynamic Study. Aust. J. Chem. 1989, 42, 1655-1670.

(100) Murphy, D.; Carroll, R.; Klonowski, J. Analysis of products of high-temperature pyrolysis of various hydrocarbons. Carbon 1997, 35, 1819-1823.

(101) Sun, Q.; Tang, Y.; Gavalas, G. Methane pyrolysis in a hot filament reactor. Energy Fuels 2000, 14, 490-494. 
Table 1. Models evaluation regarding the selected criteria.

\begin{tabular}{|c|c|c|c|c|c|c|c|c|}
\hline & \multirow{2}{*}{$\begin{array}{l}\text { Number of } \\
\text { reactions }\end{array}$} & \multirow{2}{*}{$\begin{array}{l}\text { Computation } \\
\text { time (Davis' } \\
\text { conditions) }\end{array}$} & \multicolumn{3}{|c|}{$\begin{array}{l}\text { Mean discrepancy with } \\
\text { Billaud's experiments } \\
(1263 \mathrm{~K}, 0.1 \mathrm{MPa})\end{array}$} & \multicolumn{3}{|c|}{$\begin{array}{l}\text { Mean discrepancy with } \\
\text { Davis'r computations } \\
(2000 \mathrm{~K}, 3.4 \mathrm{MPa})\end{array}$} \\
\hline & & & $\mathrm{CH} 4$ & $\mathrm{H} 2$ & $\mathrm{C} 2 \mathrm{H} 2$ & $\mathrm{CH} 4$ & $\mathrm{H} 2$ & $\mathrm{C} 2 \mathrm{H} 2$ \\
\hline GRI-MECH & 45 & $<0,5 \mathrm{sec}$ & $1,31 \%$ & $38,05 \%$ & $81,04 \%$ & $22,28 \%$ & $12,83 \%$ & $38,24 \%$ \\
\hline Leeds & 48 & $<0,5 \mathrm{sec}$ & $1,20 \%$ & $41,62 \%$ & $93,45 \%$ & $26,54 \%$ & $16,06 \%$ & $22,37 \%$ \\
\hline Konnov & 195 & $<1 \mathrm{sec}$ & $2,11 \%$ & $55,71 \%$ & $89,18 \%$ & $58,29 \%$ & $24,52 \%$ & $81,68 \%$ \\
\hline Hamdullahpur & 243 & $<1 \mathrm{sec}$ & $1,83 \%$ & $54,78 \%$ & $39,40 \%$ & $18,31 \%$ & $10,04 \%$ & $19,64 \%$ \\
\hline Sung & 245 & $<1 \mathrm{sec}$ & $1,52 \%$ & $43,69 \%$ & $68,07 \%$ & $16,68 \%$ & $11,08 \%$ & $28,43 \%$ \\
\hline Dagaut & 790 & 3'50 sec & $1,21 \%$ & $58,59 \%$ & $72,70 \%$ & $27,05 \%$ & $16,91 \%$ & $24,20 \%$ \\
\hline DEAN C1-C4 & 1108 & $5 ' 50 \mathrm{sec}$ & $1,32 \%$ & $34,96 \%$ & $65,63 \%$ & $10,63 \%$ & $10,88 \%$ & $35,57 \%$ \\
\hline DCPR & 1186 & $5 \mathrm{sec}$ & $1,75 \%$ & $48,22 \%$ & $81,00 \%$ & $22,01 \%$ & $13,93 \%$ & $26,97 \%$ \\
\hline DEAN C1 & 1284 & $7 \mathrm{sec}$ & $0,99 \%$ & $33,88 \%$ & $70,22 \%$ & $8,81 \%$ & $8,71 \%$ & $41,18 \%$ \\
\hline Westbrook & 1321 & $7 \mathrm{sec}$ & $0,56 \%$ & $21,65 \%$ & $73,35 \%$ & $23,20 \%$ & $14,56 \%$ & $36,55 \%$ \\
\hline
\end{tabular}



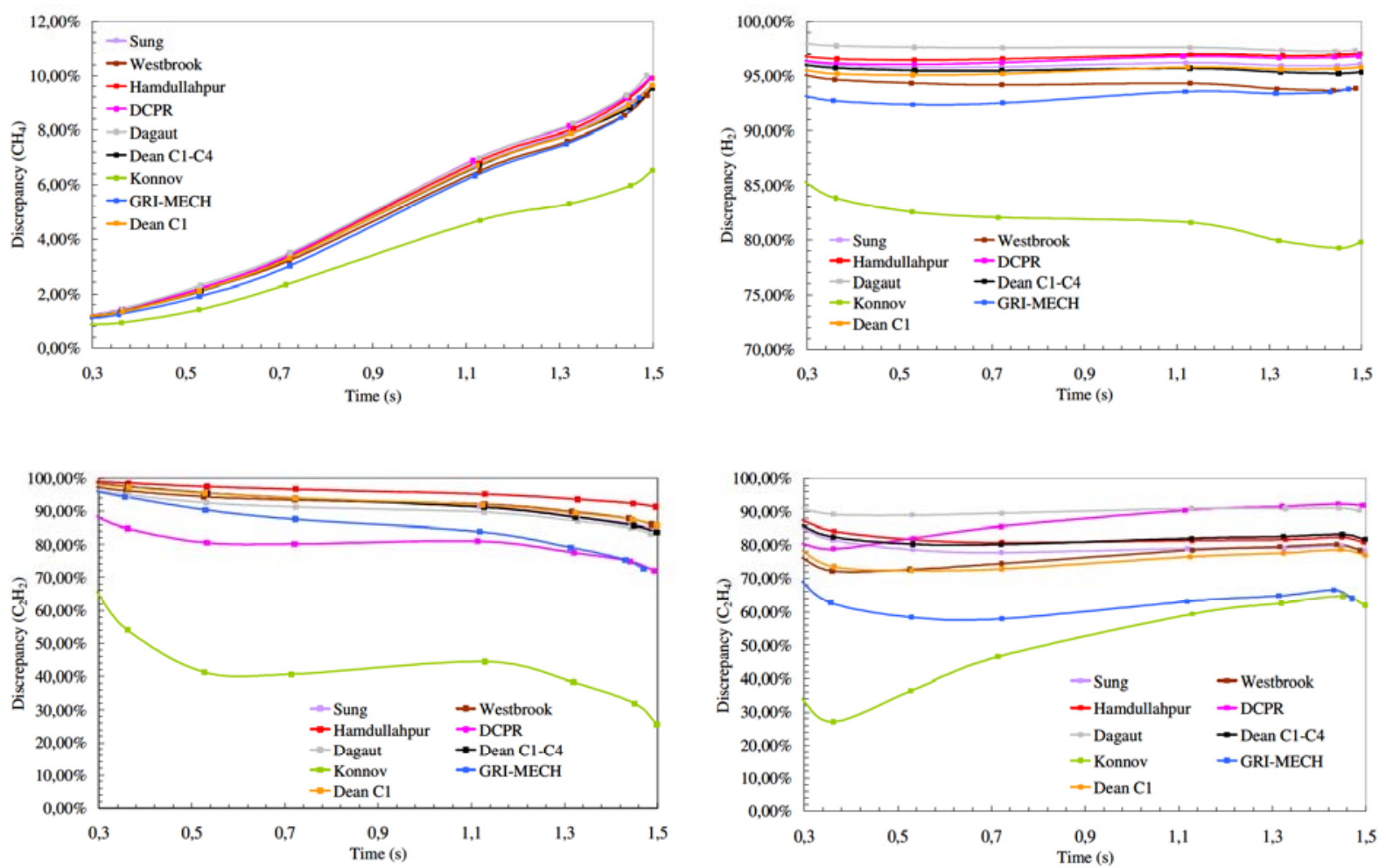

Figure 1. Comparison of numerical results (mol.\%) to Gordon's experiments ${ }^{55}(1280 \mathrm{~K}$, 0.1 MPa). a) Methane. b) Hydrogen. c) Acetylene and d) Ethylene. 

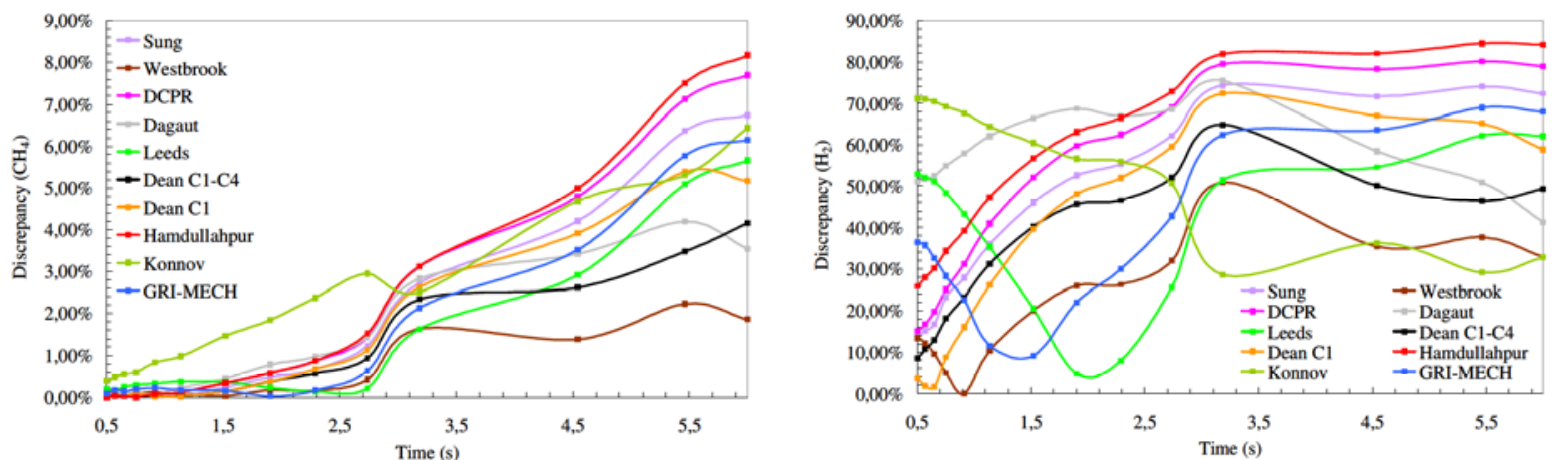

a)

b)
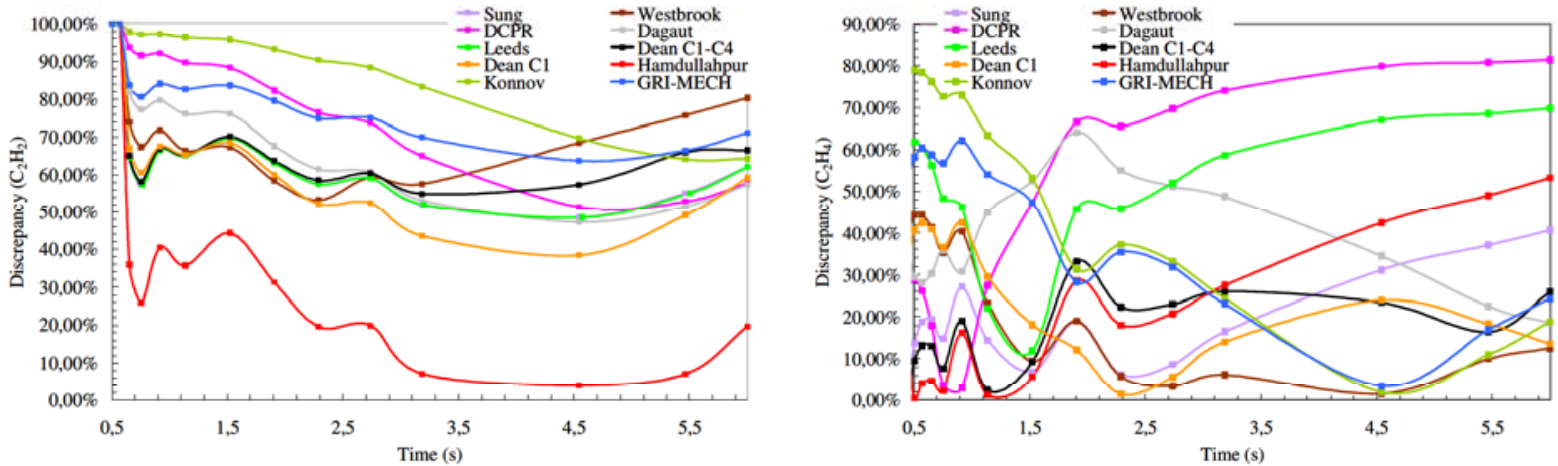

c)

d)

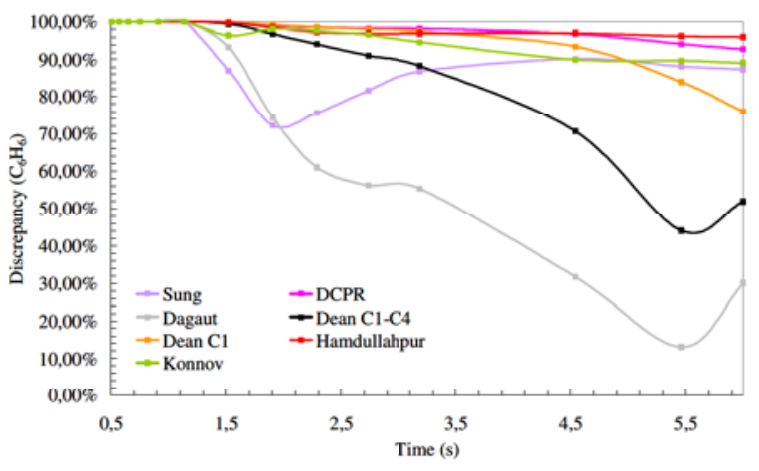

e)

Figure 2. Comparison of numerical results (mol.\%) to Billaud's experiments ${ }^{66}(1263 \mathrm{~K}$, 0.1 MPa). a) Methane. b) Hydrogen. c) Acetylene. d) Ethylene and e) Benzene. 


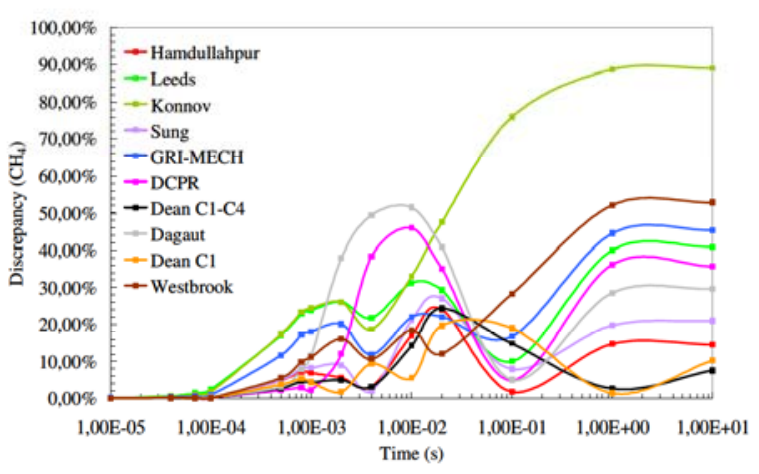

a)

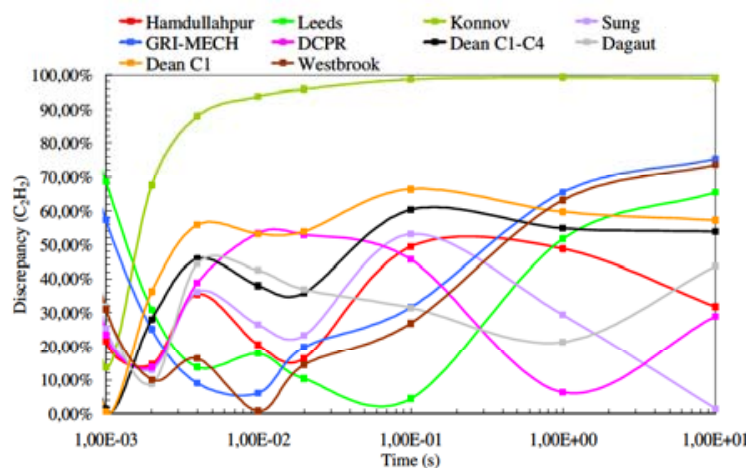

c)

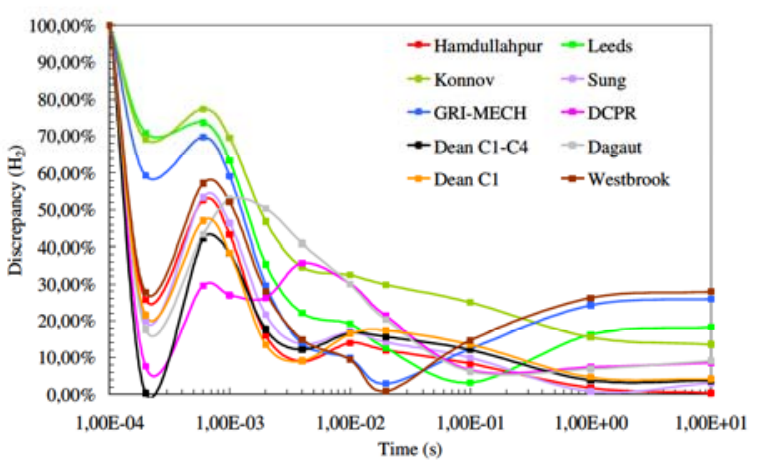

b)

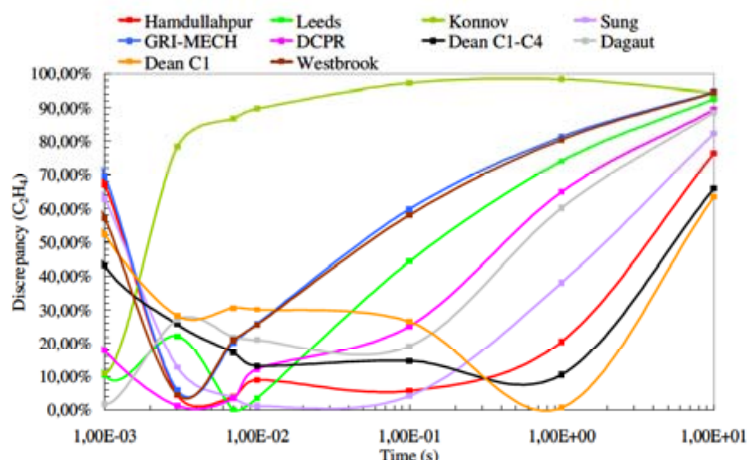

d)

Figure 3. Comparison of numerical results (mol.\%) to Davis' simulations (1700 K, $0.67 \mathrm{MPa})^{38}$.

a) Methane. b) Hydrogen, c) Acetylene and d) Ethylene. 

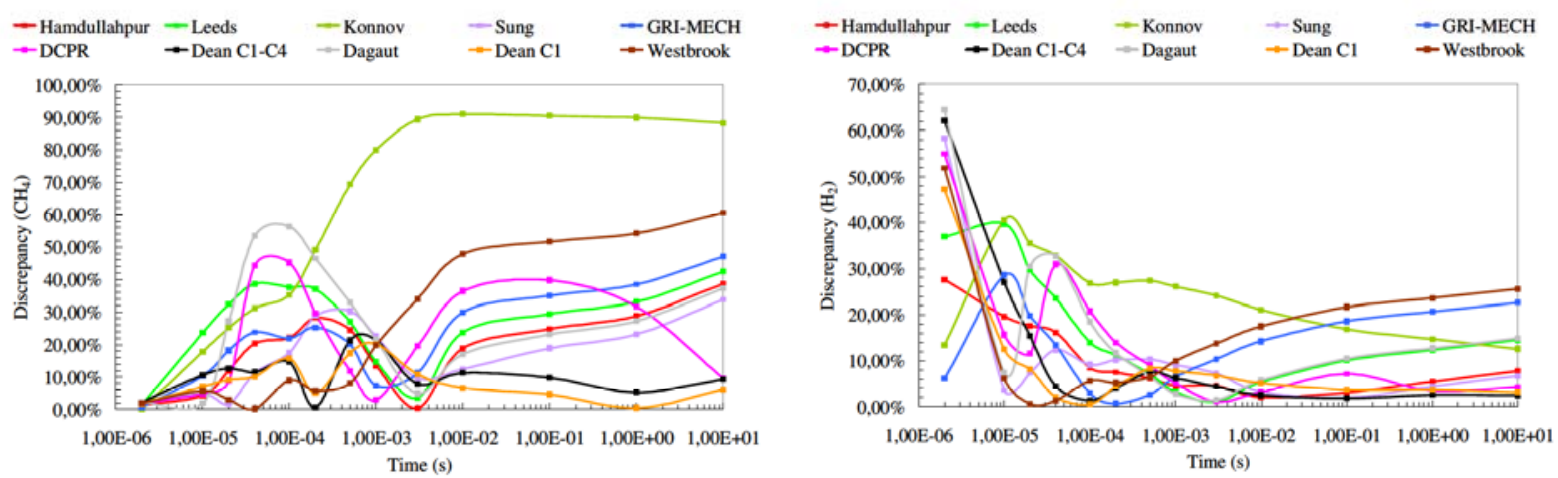

a)

b)

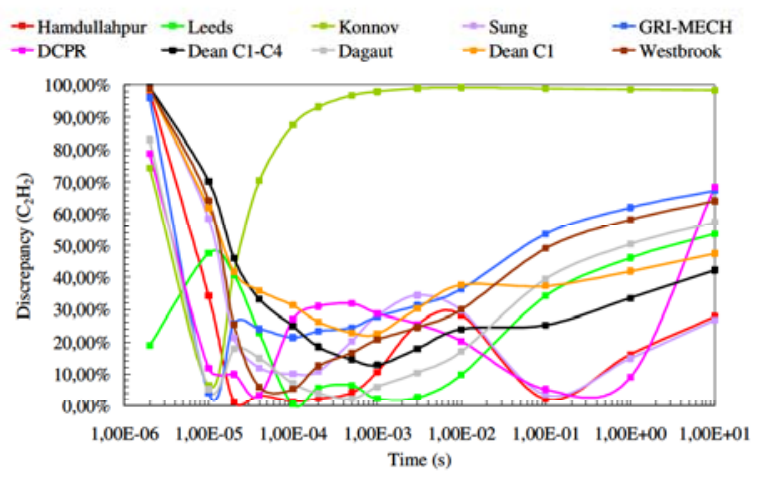

c)

Figure 4. Comparison of numerical results (mol.\%) to Davis' simulations (2000 K, $3.4 \mathrm{MPa})^{38}$.

a) Methane. b) Hydrogen and c) Acetylene. 